\title{
Early and intermediate age-related macular degeneration: update and clinical review
}

REVIEW

Clinical Interventions in Aging

3 October 2017

Number of times this article has been viewed

\author{
Alfredo García-Layana ${ }^{1-3}$ \\ Francisco Cabrera-López ${ }^{4,5}$ \\ José García-Arumín ${ }^{6-8}$ \\ Lluís Arias-Barquet ${ }^{9,10}$ \\ José M Ruiz-Moreno $3,11,12$ \\ 'Department of Ophthalmology, \\ Clínica Universidad de Navarra, \\ Pamplona, Spain; ${ }^{2}$ Sociedad Española \\ de Retina y Vítreo (SERV), Madrid, \\ Spain; ${ }^{3}$ Red Telemática de Investigación \\ Cooperativa Oftared, Instituto \\ de Salud Carlos III, Madrid, Spain; \\ ${ }^{4}$ Service of Ophthalmology, Complejo \\ Hospitalario Universitario Insular \\ Materno-Infantil de Gran Canaria, \\ Las Palmas de Gran Canaria, Spain; \\ ${ }^{5}$ Las Palmas Gran Canaria University, \\ Las Palmas de Gran Canaria, Spain; \\ ${ }^{6}$ Department of Retina and Vitreous, \\ Instituto de Microcirugía Ocular \\ (IMO), Barcelona, Spain; ${ }^{7}$ Department \\ of Ophthalmology, Universidad \\ Autónoma de Barcelona, Barcelona, \\ Spain; ${ }^{8}$ Hospital Universitario \\ Valle Hebrón, Barcelona, Spain; \\ 'Section of Medical-Surgical Retina, \\ Service of Ophthalmology, Hospital \\ Universitari de Bellvitge, Barcelona, \\ Spain; ${ }^{10}$ University of Barcelona, \\ Barcelona, Spain; "Universidad \\ Castilla-La Mancha, Albacete, Spain; \\ ${ }^{12}$ Vissum Corporación Oftalmológica, \\ Madrid, Spain
}

Correspondence: Alfredo García-Layana Department of Ophthalmology, Clínica Universidad de Navarra, Avenida de Pío XII 36, E-3 I008 Pamplona, Spain

Tel +34948296331

Email aglayana@unav.es

\begin{abstract}
Age-related macular degeneration (AMD) is the leading cause of irreversible central vision loss in developed countries. With the aging of population, AMD will become globally an increasingly important and prevalent disease worldwide. It is a complex disease whose etiology is associated with both genetic and environmental risk factors. An extensive decline in the quality of life and progressive need of daily living assistance resulting from AMD among those most severely affected highlights the essential role of preventive strategies, particularly advising patients to quit smoking. In addition, maintaining a healthy diet, controlling other risk factors (such as hypertension, obesity, and atherosclerosis), and the use of nutritional supplements (antioxidants) are recommendable. Genetic testing may be especially important in patients with a family history of AMD. Recently, unifying criteria for the clinical classification of AMD, defining no apparent aging changes; normal aging changes; and early, intermediate, and late AMD stages, are of value in predicting AMD risk of progression and in establishing recommendations for the diagnosis, therapeutic approach, and follow-up of patients. The present review is focused on early and intermediate AMD and presents a description of the clinical characteristics and ophthalmological findings for these stages, together with algorithms for the diagnosis and management of patients, which are easily applicable in daily clinical practice.

Keywords: age-related macular degeneration, early AMD, intermediate AMD, risk factors, classification, prevention, nutritional supplementation
\end{abstract}

\section{Background}

Age-related macular degeneration (AMD) is the main cause of blindness in the developed world in subjects aged $\geq 55$ years, mainly with risk factors and genetic predisposition, with the number of patients affected being counted in millions and likely to increase with the population longevity. ${ }^{1}$ Irreversible central vision loss is highly incapacitating in multiple physical, social, and emotional areas of patients as well as is leading to increased health resource utilization and high societal cost burden. ${ }^{2}$ A systematic review of 39 population-based studies of AMD published before 2013 showed a pooled prevalence for an age range of 45-85 years of $8.7 \%$. $^{3}$ Early detection and treatment are critical in increasing the likelihood of retaining good and functional vision. However, despite the growth in treatment options for this disease, there is no current curative therapy. Of critical importance is attention to modifiable risk factors and routine ophthalmic monitoring for opportunities to provide timely interventions in the individual patients. ${ }^{4,5}$

The mechanisms of AMD pathogenesis are still poorly defined. In fact, the multifactorial nature of the disease, the complexity of the visual system, and the enigma of aging processes make AMD a complex pathology, in which a correct and prompt diagnosis is a key point. Two types of AMD, the "dry" (or atrophic) and "wet" 
(or neovascular) forms of the disease, have been extensively described. ${ }^{6,7}$ However, the current clinical classification of AMD defines three stages according to the severity of fundus lesions (drusen size and pigmentary abnormalities) assessed within 2 disc diameters of the fovea in persons aged $>55$ years. ${ }^{8}$ This basic clinical classification scale defining early, intermediate, and late AMD, including geographic atrophy and neovascularization, also is of value in predicting risk estimates of progressing to advanced AMD stages. ${ }^{8}$

There is a paucity of updated and comprehensive information focused exclusively on early stages of AMD, which can be of the interest of clinicians involved in the care of elderly people. Therefore, the objective of the present review was to present a description of the clinical characteristics and ophthalmological findings of early and intermediate stages of AMD, together with algorithms for the diagnosis and management of patients with direct applicability in daily practice. Unlike neovascular (wet) AMD, early stages (early and intermediate) of AMD are not usually the focus of an in-depth review.

\section{Risk factors}

The initial cause of AMD is unknown, although age, genetic factors, and active smoking have been clearly identified as risk factors for AMD. One of the most significant factors associated with age is focal deposition of acellular detritus between the retinal pigment epithelium (RPE) and the Bruch's membrane. These deposits known as drusen appear as small yellow points in the macula and peripheral retina. Phagocytosis of shed photoreceptor rod outer segments by the RPE is essential for retinal function. With age, RPE becomes less efficient with the accumulation of residual bodies that may cause loss of RPE cells. Changes in the thickness or composition of the Bruch's membrane associated with age determine an important reduction of fluid and nutrient transport, which are vital for the function of photoreceptors. Age also causes a 50\% reduction in the thickness of choroidal vessels and an alteration of the sinusoid structure, which together with thickness of the Bruch's membrane cause hypoxia, responsible for secretion of vascular endothelial growth factors, which contribute to the development of neovessels. On the other hand, an increase in the rigidity of the scleral due to age, dyslipidemia, and particularly atherosclerosis may affect clearance of lipoproteins, which accumulate in the form of drusen in the subretinal space contributing to atrophy of photoreceptors. These changes are reflected by the increasing prevalence of AMD as subjects are getting older. Disease prevalence for late AMD can peak near $10 \%$ in persons aged $>80$ years. The prevalence of late AMD is $1.4 \%$ at the age of 70 years, raising to $5.6 \%$ at age of 80 and to $20 \%$ at age of $90 .^{9}$

In addition to age-related changes, it has been shown that genetic factors significantly contribute to risk for advanced AMD. ${ }^{10,11}$ About 20 genes involved in the pathogenesis of AMD have been identified, the most important being CFH, C3, C2, ARMS2, FB, CFHR4, CFHR5, and F13B. The $C F H Y 402 H$ polymorphism is strongly associated with AMD, playing a role in almost $60 \%$ of AMD at the population level. ${ }^{12}$ Prevalence rates of this polymorphism vary by race, with higher percentages in Caucasians (39\%) and black people (30\%) than in Asian populations (7\%). ${ }^{12}$ The importance of this factor has propitiated the development of commercially available genetic testing kits, which in addition to phenotype data are of value to assess the risk of progression of the disease. ${ }^{13,14}$

Epidemiological studies have shown that cigarette smoking increases the risk of AMD 2- to 4-fold compared to patients who never smoked. ${ }^{15,16}$ It is postulated that smoking affects the pathogenesis of AMD by a variety of mechanisms promoting oxidative damage, inducing angiogenesis, impairing the choroidal circulation, and by activating the immune system including the complement pathway. ${ }^{17-19}$ Stopping smoking reduces the risk of AMD, and after 20 years of cessation, the risk of developing AMD is the same as for nonsmokers. Moreover, for people who are homozygous for the $\mathrm{Y} 402 \mathrm{H}$ allele in $\mathrm{CFH}$, smoking has a multiplicative effect on the risk of AMD. ${ }^{20}$ In this respect, it has been shown that genetic risk information for AMD can influence motivation to stop smoking. ${ }^{21}$

Other risk factors for AMD include hypertension, atherosclerosis, family history of AMD, high body mass index, high-fat diet, low intake of antioxidants and zinc, previous cataract surgery, history of cardiovascular disease, higher plasma fibrinogen, and diabetes..$^{22-24}$

\section{Clinical classification}

The development of a novel clinical classification of AMD based on an evidence-based investigation using a Delphi process has been shown to be a very valuable tool in the therapeutic approach of patients with AMD. ${ }^{8}$ This classification system focuses on the clinical phenotype associated with the development of large drusen and pigmentary abnormalities, leading to neovascular AMD, geographic atrophy, or both. The unified classification scheme is easy to use in daily practice because it is based on fundus lesions assessed within 2 disc diameters of the fovea in people aged $>55$. 
As the first step, phenotype characteristics are limited to those that can be identified by common ophthalmological office equipment (ophthalmoscope and slit lamp with accessory lenses), although other imaging technologies and visual function evaluation may be necessary to refine the phenotypes of early, intermediate, and late stages of AMD.

The first proposal has been to use the single term "agerelated macular degeneration" for the disease. In addition, there is a clear differentiation between the stages of "no apparent aging changes" or "normal aging changes" characterized by the presence of drupelets only (small drusen $\leq 63 \mu \mathrm{m}$ ) and "early," "intermediate," and "late" AMD stages. As shown in Table 1, the severity stages (ie, early, intermediate, and late AMD) are established according to drusen size and AMD pigmentary abnormalities. ${ }^{8}$ AMD pigmentary abnormalities are defined as hyperpigmentation or hypopigmentation present within 2 disc diameters of the center of the macula in eyes with drusen $\geq 63 \mu \mathrm{m}$ in diameter and without known retinal disease entities or other reasons for such abnormalities. Figures 1-11 show the illustrative cases of early, intermediate, and late AMD.

Interestingly, a 5-year risk scale using data of the AgeRelated Eye Disease Study (AREDS ${ }^{25}$ and based on a combination of one or more large drusen $(\geq 125 \mu \mathrm{m})$ and AMD pigmentary abnormalities in the right and left eyes was also developed. ${ }^{25}$ According to ophthalmological findings, a maximum score of 2 per eye with a maximum score of 4 per patient can be established (Table 2). The 5-year risk for developing AMD increases by a factor of 100 between a score of 0 and a score of 4 . The risk of 5-year progression to late AMD is $0.5 \%$ for score 0 (normal aging changes), $3 \%$ for score $1,12 \%$ for score $2,25 \%$ for score 3 , and $50 \%$ for score 4 . The risk estimate can be further modified up or

Table I Clinical classification of AMD based on phenotype characteristics

\begin{tabular}{ll}
\hline Classification & Characteristics \\
\hline No abnormal & No aging changes: \\
findings & - Absence of drusen \\
& - No pigmentary abnormalities \\
& Normal aging changes: \\
& - Drupelets only (small drusen $\leq 63 \mu \mathrm{m}$ ) \\
& - No pigmentary abnormalities \\
Early AMD & Medium-sized drusen $>63 \mu \mathrm{m}$ and $\leq \mathrm{I} 25 \mu \mathrm{m}$ \\
Intermediate AMD & - Large drusen $>$ I $25 \mu \mathrm{m}$ and/or pigmentary \\
& abnormalities \\
Late AMD & Neovascular AMD and/or any \\
& geographic atrophy \\
\hline
\end{tabular}

Abbreviation: AMD, age-related macular degeneration.

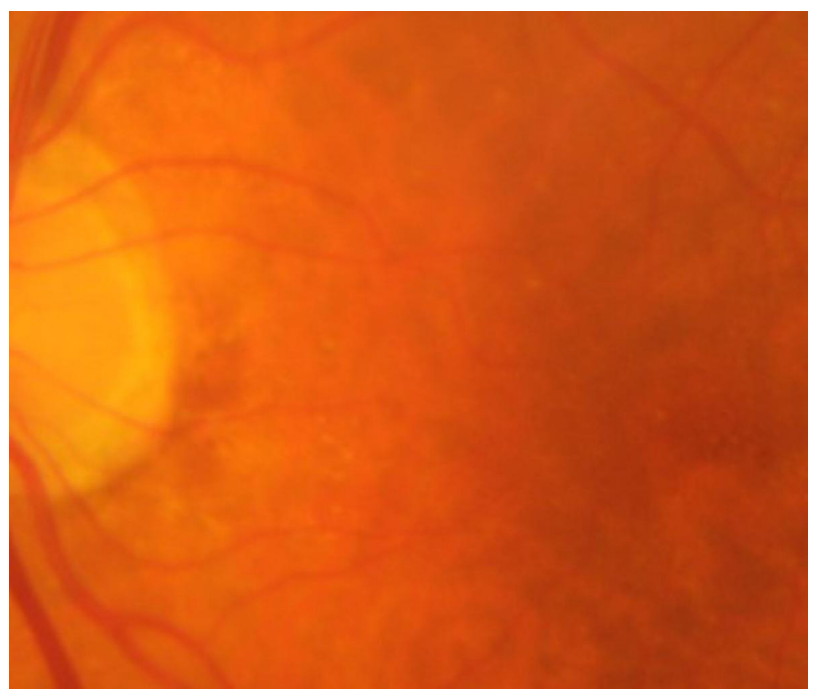

Figure I Normal aging changes, with drupelets only (small drusen $\leq 63 \mu \mathrm{m}$ ) and no pigmentary abnormalities.

down according to the presence or absence of other known risk factors (eg, smoking and genetic risk).

\section{Diagnosis}

It is important to recognize symptoms suspicious of AMD that should alert clinicians to refer the patient to the specialist for a complete assessment and to determine the urgency of treatment. In a person aged $>55$ years with good visual acuity (VA), alarming signs include the following: 1) progressive or sudden decreased vision not improved with optic correction; 2) central field defect (whether absolute or relative); 3) metamorphopsia, micropsias, or macropsias; or 4) difficulties in

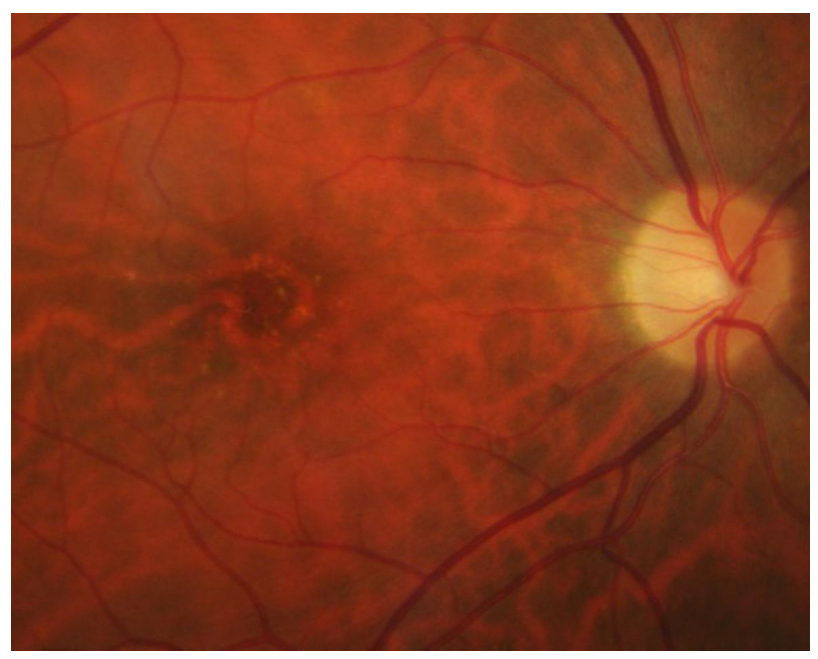

Figure 2 Early AMD with medium-sized drusen $>63 \mu \mathrm{m}$ and $\leq 125 \mu \mathrm{m}$ and no pigmentary abnormalities.

Abbreviation: AMD, age-related macular degeneration. 


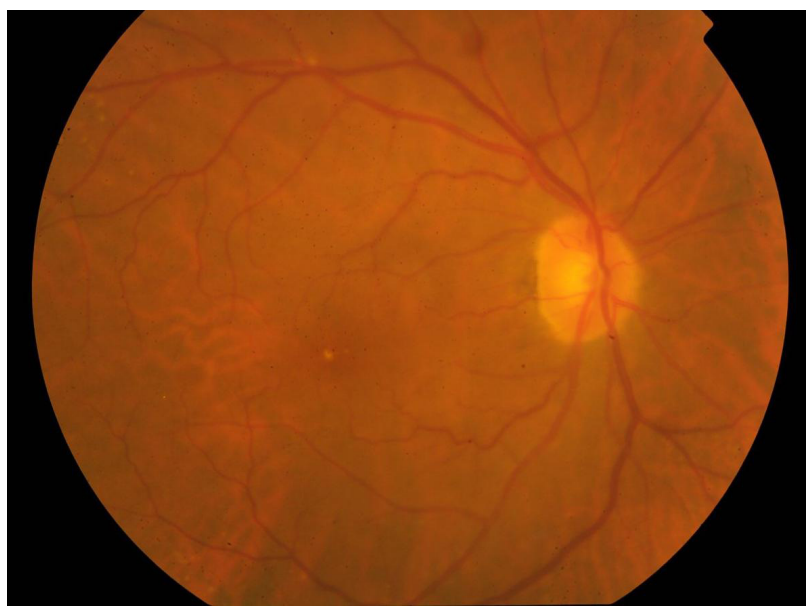

Figure 3 To define intermediate AMD is enough to have one or more large drusen ( $\geq 125 \mu \mathrm{m}$ in the smallest diameter), a distance approximating the width of a major branch retinal vessel crossing the optic disc margin.

Abbreviation: AMD, age-related macular degeneration.

daily life activities (eg, watching television, going down stairs, recognizing people, and going around a corner).

Metamorphopsia is a key symptom in the assessment of a patient with AMD. Metamorphopsias is a hallmark sign in patients with macular diseases and can be easily recognized using the Amsler grid or M-charts. ${ }^{26,27}$ In the preferential hyperacuity perimeter (PHP) test, a single straight dotted line with a few dots out of alignment is flashed across different macular loci over a macular field of $14^{\circ} \times 14^{\circ}$, and the patient uses a stylus to touch the screen where he had experienced a distortion in the line. Any distortion perceived by the patient is automatically recorded and analyzed, and a macular map showing the area of distortion and the intensity of metamorphopsia is displayed. Although the superiority of this test over

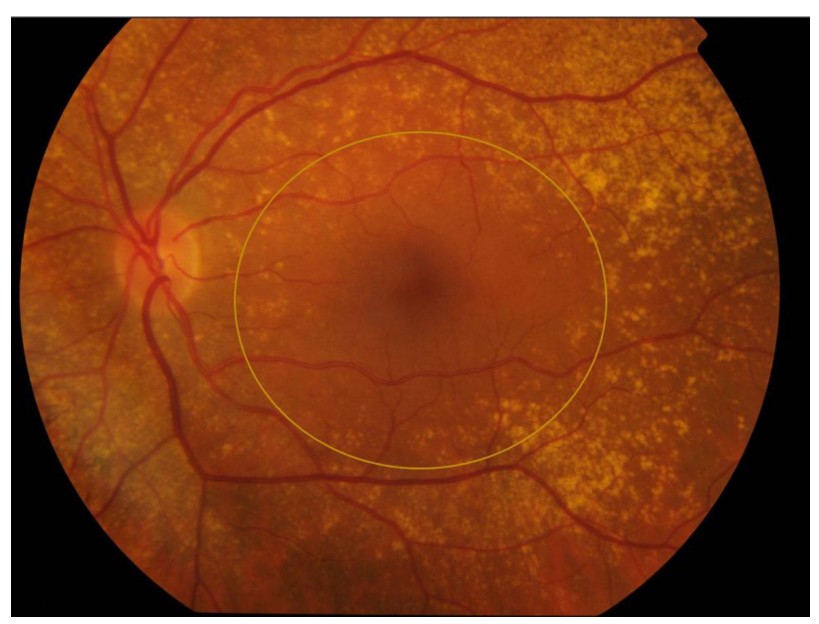

Figure 4 Intermediate AMD with small, intermediate, and large drusen, most of them outside the macula center.

Note: The yellow circle represents a size of 2 disc diameters showing that there are also drusen inside the macular center.

Abbreviation: AMD, age-related macular degeneration.

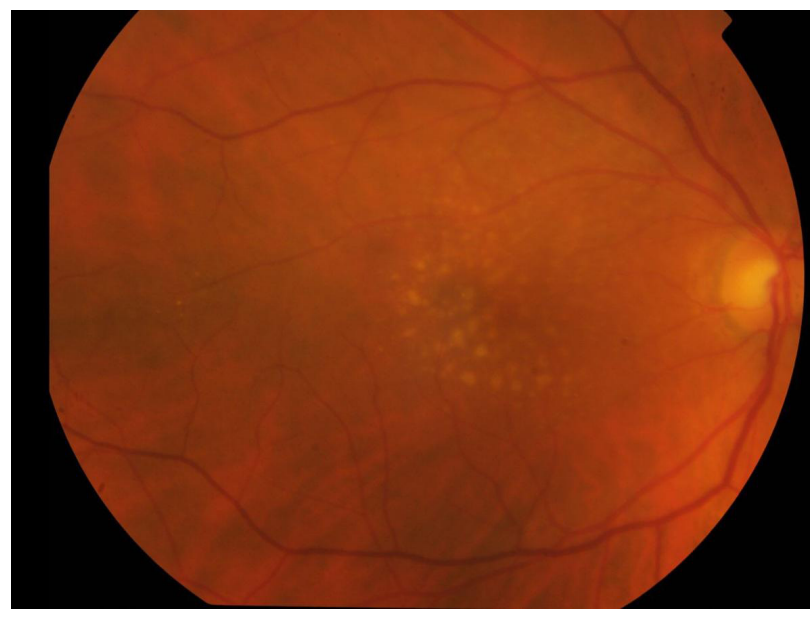

Figure 5 Intermediate AMD with small, intermediate, and large drusen, most of them in the macula center.

Abbreviation: AMD, age-related macular degeneration.

the Amsler grid in patients with AMD has been reported, ${ }^{28}$ similar test performance characteristics for both the Amsler grid and PHP to rule out wet AMD in the screening setting have been found. ${ }^{29}$ However, the disadvantage of the PHP is its high cost. On the other hand, the macular mapping test (MacuFlow),${ }^{30}$ which can be used at home because it is freely accessible through Internet, requires the cooperation of someone who is trained and with good VA as well as considerable intellectual ability, making its universal use as a screening instrument difficult. The association of the Amsler grid with the near vision and reading optotype has been shown to be useful for early self-diagnosis in neovascular AMD. ${ }^{31}$

A visit to the ophthalmologist is essential for a correct diagnosis of AMD, including fundus examination with dilated pupils or nonmydriatic chamber and assessment of the

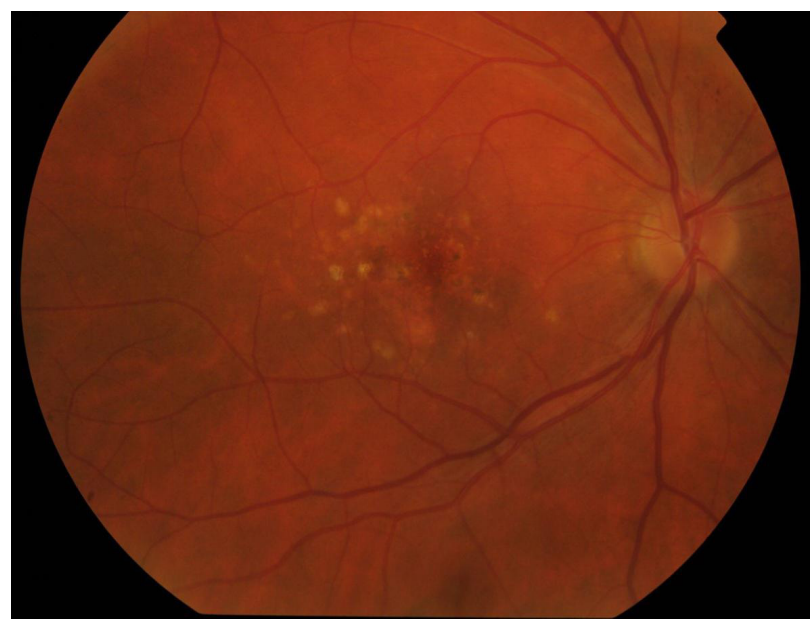

Figure 6 Intermediate AMD with hyperpigmentary or hypopigmentary abnormalities associated with some drusen $\geq 63 \mu \mathrm{m}$ in diameter.

Abbreviation: AMD, age-related macular degeneration. 


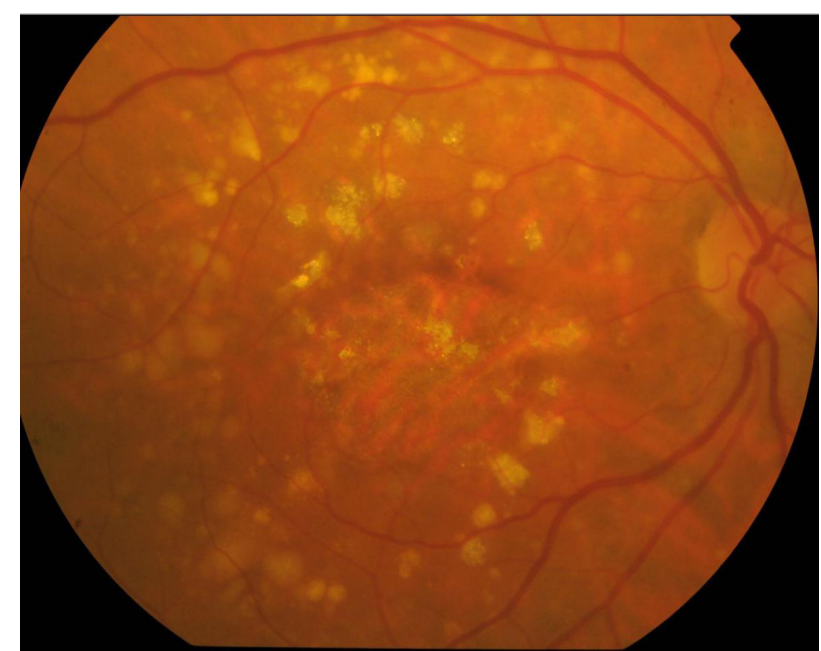

Figure 7 Late AMD with large drusen, hyperpigmentary and hypopigmentary abnormalities, and geographic atrophy.

Abbreviation: AMD, age-related macular degeneration.

VA (Early Treatment Diabetic Retinopathy Study optotype). Optical coherence tomography (OCT) is recommendable, whereas fluorescein angiography is indicated in patients with suspicion of choroidal neovascularization membrane. In clinical practice, indispensable work-up studies should include dilated fundus examination and VA measurement. Evaluation of the optic fundus combined with information provided by the new clinical classification of AMD is a basic tool for the diagnosis of the disease, identification of AMD stage in the individual patient, and planning of therapeutic strategies and follow-up.

Commercial genetic testing using a sample of saliva and examining a number of main genetic biomarkers for AMD are now widely available through physicians' offices.

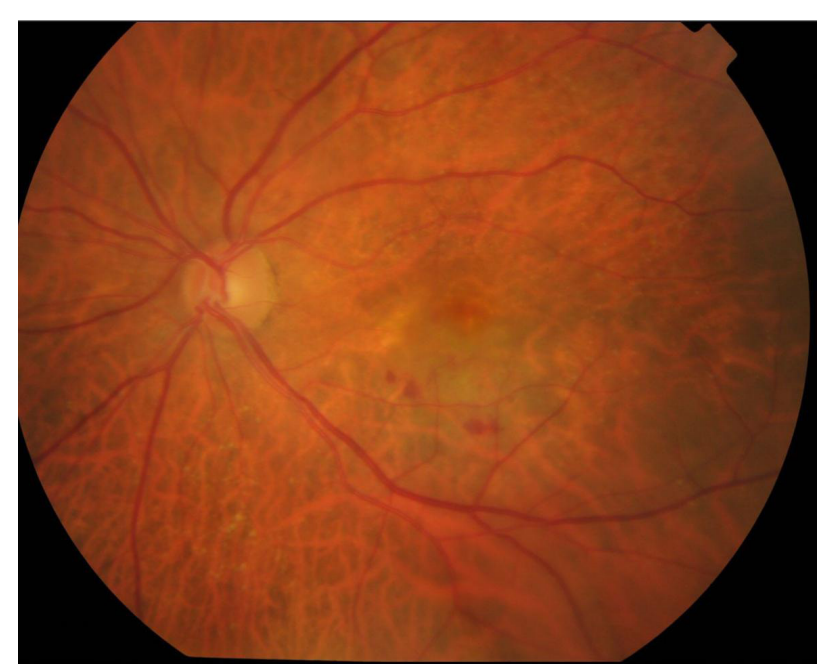

Figure 8 Late neovascular AMD with a choroidal neovascularization surrounding by subretinal hemorrhages.

Abbreviation: AMD, age-related macular degeneration.

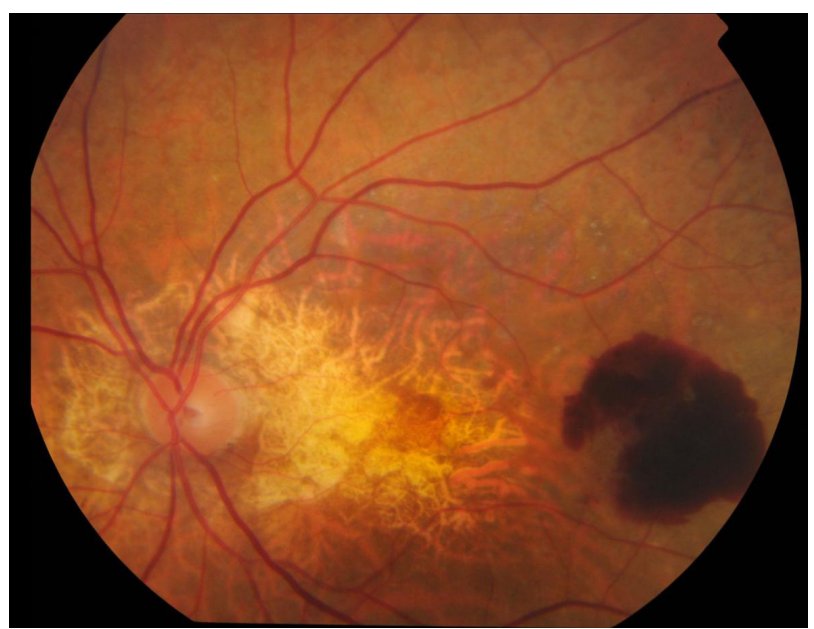

Figure 9 Late AMD with both neovascular signs (choroidal neovascularization with subretinal hemorrhages) and geographic atrophy.

Abbreviation: AMD, age-related macular degeneration.

Genetic information has been shown to be of value to predict progression to the advanced forms of AMD, choroidal neovascularization, and geographic atrophy ${ }^{32-34}$ as well as to improve patient management. However, the routine use of genetic testing is not supported by the existing literature and is not recommended at this time. Prospectively designed clinical trials are still needed to validate the use of genetic testing in AMD. ${ }^{35}$

In the presence of changes in the epiretinal membrane, fundus autofluorescence imaging will help to identify better the characteristics and details of these findings (Figure 11).

\section{Management and follow-up}

Recommendations regarding the therapeutic approach and follow-up of patients are based on a definitive diagnosis of the

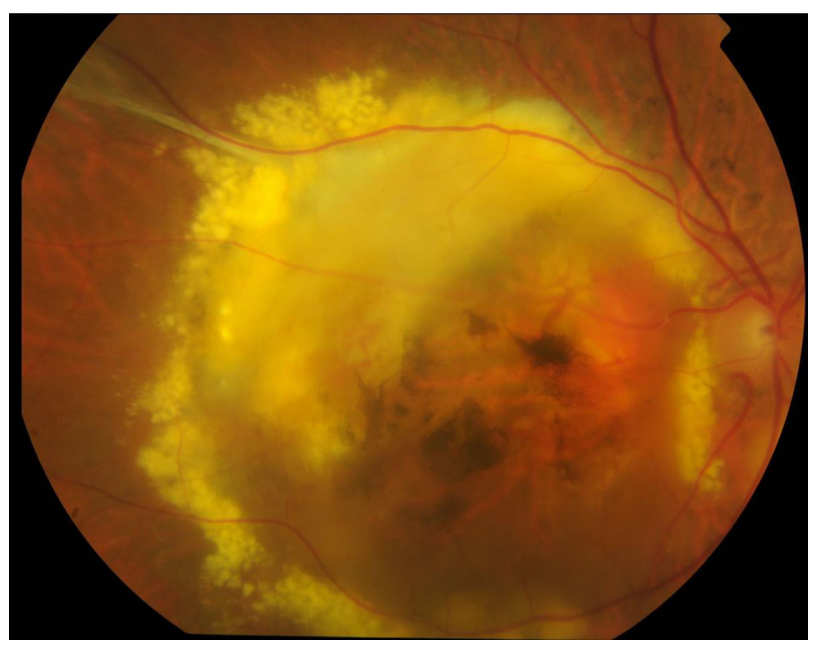

Figure 10 Late AMD in a disciform stage secondary to neovascular AMD.

Note: Subretinal fibrosis, lipid exudates, hyperpigmentary and hypopigmentary abnormalities, and geographic atrophy are present.

Abbreviation: AMD, age-related macular degeneration. 


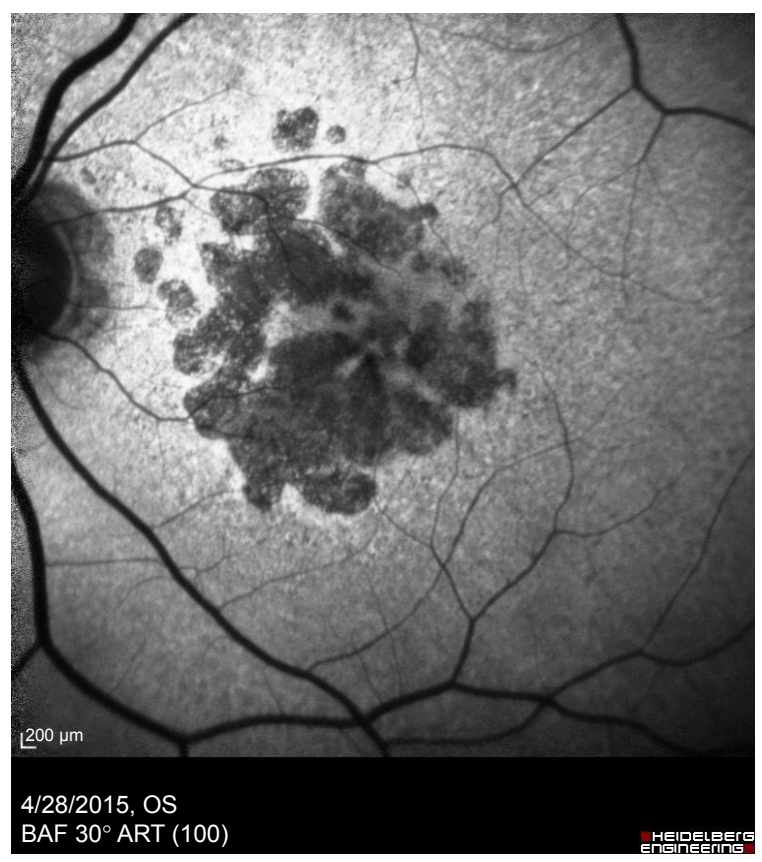

Figure I I Fundus autofluorescence picture of the left eye of a patient with advanced geographic atrophy AMD.

Abbreviation: AMD, age-related macular degeneration.

stage of the disease based on the results of ophthalmological examinations and application of the clinical classification of AMD.

In patients with early AMD, it is important to identify modifiable lifestyle risk factors especially to advise to quit

Table 2 Ophthalmological findings determined by clinical examination or evaluation of fundus photographs to assess risk categories for late AMD

\begin{tabular}{|c|c|c|c|}
\hline Eyes & Findings & Score & $\begin{array}{l}\text { Risk } \\
\text { score }\end{array}$ \\
\hline \multirow[t]{2}{*}{ Right } & $\begin{array}{l}\text { I) One or more large drusen }(\geq 125 \mu \mathrm{m} \\
\text { in the smallest diameter), a distance } \\
\text { approximating the width of a major branch } \\
\text { retinal vessel crossing the optic disc margin }\end{array}$ & $\begin{array}{l}\text { No }=0 \\
\text { Yes }=I\end{array}$ & I \\
\hline & $\begin{array}{l}\text { 2) Any definitive hyperpigmentary or } \\
\text { hypopigmentary abnormalities associated } \\
\text { with at least some drusen } \geq 63 \mu \mathrm{m} \text { in } \\
\text { diameter, but not associated with known } \\
\text { retinal disease entities or other reasons for } \\
\text { such abnormalities }\end{array}$ & $\begin{array}{l}\text { No }=0 \\
\text { Yes }=I\end{array}$ & I \\
\hline \multirow[t]{2}{*}{ Left } & $\begin{array}{l}\text { I) One or more large drusen ( } \geq 125 \mu \mathrm{m} \\
\text { in the smallest diameter), a distance } \\
\text { approximating the width of a major branch } \\
\text { retinal vessel crossing the optic disc margin }\end{array}$ & $\begin{array}{l}\text { No }=0 \\
\text { Yes }=I\end{array}$ & I \\
\hline & $\begin{array}{l}\text { 2) Any definitive hyperpigmentary or } \\
\text { hypopigmentary abnormalities associated } \\
\text { with at least some drusen } \geq 63 \mu \mathrm{m} \text { in } \\
\text { diameter, but not associated with known } \\
\text { retinal disease entities or other reasons for } \\
\text { such abnormalities }\end{array}$ & $\begin{array}{l}\text { No }=0 \\
\text { Yes }=I\end{array}$ & I \\
\hline
\end{tabular}

Abbreviation: AMD, age-related macular degeneration. smoking $^{36-39}$ and to improve a balanced and healthy diet rich in fruits, vegetables (natural antioxidants), and bluefish (the primary source of omega-3 polyunsaturated fatty acids [PUFAs], such as docosahexaenoic acid [DHA] and eicosapentaenoic acid [EPA]). ${ }^{40-51}$ Other risk factors (eg, hypertension, atherosclerosis, and overweight) present in the individual patient should be controlled. ${ }^{52}$ Genetic testing may be recommendable based on a personalized approach, with particular indication in patients with a family history of AMD.$^{35}$ The patient should be instructed to use the Amsler grid with the lines on a black background to assess the appearance of any distortions or breaks in the lines of the grid. In the absence of any manifestation suggestive of progression of AMD, patients should be followed at 12-month intervals.

In patients with intermediate $\mathrm{AMD}$, recommendations are focused on evaluation and correction of risk factors especially on quitting smoking and taking antioxidants as a dietary supplementation. ${ }^{35,52}$ In addition, self-assessment using the Amsler grid on a black background together with the reading optotype should be recommended, with follow-up controls scheduled at 6-month intervals. However, it is important to warn the patient that if he/she perceives a sudden change in vision before the next visit, an urgent consultation with the ophthalmologist is necessary.

Different studies have provided consistent evidence of the benefits of treatment with antioxidants (ie, vitamin E, vitamin $\mathrm{C}$, lutein and zeaxanthin, zinc, and copper) in the intermediate AMD stage. The AREDS ${ }^{53}$ showed a statistically significant odds reduction for the development of advanced AMD with antioxidants (ie, vitamin C, vitamin E, and beta-carotene) plus zinc. In the AREDS $2,{ }^{54}$ lutein and zeaxanthin were used as an appropriate carotenoid substitute. The addition of DHA and EPA to the AREDS formulation was not associated with a significant improvement in the risk reduction of progression to late AMD in this population. However, compared to the AREDS, the population was older, the patients had a more severe disease, and the number of participants in each study group was smaller. Antioxidant, vitamin, and mineral supplementation as per the original AREDS and AREDS2 trials should be considered in patients with intermediate AMD. Numerous studies have shown the benefits of higher dietary intake of food rich in omega-3 long-chain PUFAs to reduce the risk of AMD and the progression of the disease, ${ }^{44-51,55}$ as well as the risk of late AMD in cases of genetic susceptibility. ${ }^{56}$ Although the role of omega-3 fatty acids on the pathogenic mechanisms of AMD is currently unresolved, wide circumstantial evidences from epidemiological studies and preclinical in vivo and in vitro research are strongly supportive..$^{57,58}$ 
Table 3 Recommendations for the diagnosis and management of early AMD

\begin{tabular}{lll}
\hline Diagnosis & Recommendations & Follow-up \\
\hline Identification of risk factors & Self-assessment with the Amsler grid Controls scheduled every I2 months & \multicolumn{1}{c}{ Co the absence of clinical manifestations } \\
Basic indispensable ophthalmological examinations: & on a black background suggestive of the progression of disease \\
- Visual acuity & Correction of modifiable risk factors: \\
- Dilated fundoscopy & - Smoking cessation \\
Recommendable complementary studies: & - Healthy diet \\
- Spectral domain OCT or swept-source OCT & - Other factors (eg, hypertension, \\
- Color fundus Photography & obesity, and atherosclerosis) \\
Genetic test (pending for validation in prospective clinical trials) & \\
\hline
\end{tabular}

Abbreviations: AMD, age-related macular degeneration; OCT, optical coherence tomography.

Experimental studies have shown that lead and cadmium accumulate in human ocular tissues, particularly in the RPE and choroid. ${ }^{59}$ An in vitro study on a human RPE cell line showed a reduction in intracellular cadmium $(\mathrm{Cd}[2+])$ levels by coexposure with manganese ${ }^{60}$ In humans, cadmium content in retinal tissue seems to increase as a function of age and tobacco smoking. In addition, higher cadmium levels have been found in neural retina and RPE for AMD eyes compared with controls. ${ }^{61,62}$ In this respect, whether heavy metal adsorbents (eg, natural zeolites) might have an application for removing metal ions in eye tissues is still speculative.

Melatonin has been shown to scavenge hydroxyl radicals and to protect RPE from oxidative damage. It has been postulated that the physiological decrease of melatonin in aged people may be an important factor in RPE dysfunction. Clinical studies have shown that the daily use of $3 \mathrm{mg}$ melatonin seems to protect the retina and to delay macular degeneration. ${ }^{63-65}$ Integrin peptide therapy is also an emerging new class of treatment for wet AMD. ${ }^{66}$ The understanding of AMD pathogenesis could provide innovative therapeutic approaches to AMD. Therefore, more research into the early phases of AMD is warranted.
Finally, Tables 3 and 4 show the algorithms for the diagnosis, management, and follow-up of patients with early and intermediate AMD. These proposed algorithms are simple and easy to be implemented in clinical practice.

\section{Concluding remarks}

The recent clinical classification of AMD is a remarkable advance in unifying criteria for correct diagnosis of the different stages of the disease, which is essential to determine the risk of progression and the therapeutic approach of patients. Smoking is a crucial modifiable risk factor for AMD, and all efforts should be made to advise and help patients to quit. Minimum examinations required in clinical practice for screening of AMD are measurement of VA and dilated fundus examination. OCT and fundus autofluorescence are rapid, easy, and reliable studies recommendable in the assessment of patients with AMD. Metamorphopsia is a hallmark sign that can be detected and quantified using simple methods, such as the Amsler grid on a black background. A correct and healthy diet is recommendable in early AMD, whereas the use of nutritional supplements (antioxidants) is particularly indicated in the intermediate stage of the disease. In the presence of any change of vision, an urgent consultation with the

Table 4 Recommendations for the diagnosis and management of intermediate AMD

\begin{tabular}{ll}
\hline Diagnosis & Recommendations \\
\hline Identification of risk factors & $\begin{array}{l}\text { Self-assessment with the Amsler grid } \\
\text { on a black background } \\
\text { Correction of modifiable risk factors: }\end{array}$ \\
$\begin{array}{l}\text { Basic indispensable ophthalmological } \\
\text { examinations: }\end{array}$ & $\begin{array}{l}\text { Controls scheduled every } 6 \text { months. } \\
\text { If progression to advanced AMD }\end{array}$ \\
- Visual acuity & - Healthy diet \\
- Dilated fundoscopy & Other factors (eg, hypertension, \\
Recommendable complementary studies: & obesity, and atherosclerosis) \\
- Spectral domain OCT or swept-source OCT & Antioxidants (nutritional supplements) \\
- Color fundus Photography & \\
- Fundus autofluorescence & \\
Genetic test (pending for validation in prospective & Urgent consultation with the \\
clinical trials). It is especially recommendable in & ophthalmologist in the presence of \\
patients with a family history of AMD & sudden vision changes \\
\hline
\end{tabular}

Abbreviations: AMD, age-related macular degeneration; OCT, optical coherence tomography. 
ophthalmologist is mandatory. In patients with intermediate AMD, follow-ups should be scheduled every 6 months with prompt referral to a retinal specialist when the progression of the disease is detected.

\section{Acknowledgment}

The authors thank Marta Pulido, MD, PhD, for editing the manuscript and for editorial assistance.

\section{Disclosure}

The authors report no conflicts of interest in this work.

\section{References}

1. Pennington KL, DeAngelis MM. Epidemiology of age-related macular degeneration (AMD): associations with cardiovascular disease phenotypes and lipid factors. Eye Vis (Lond). 2016;3:34.

2. Cruess AF, Zlateva G, Xu X, et al. Economic burden of bilateral neovascular age-related macular degeneration: multi-country observational study. Phamacoeconomics. 2008;26(1):57-73.

3. Wong WL, Su X, Li X, et al. Global prevalence of age-related macular degeneration and disease burden projection for 2020 and 2040: a systematic review and meta-analysis. Lancet Glob Health. 2014;2: e106-e116.

4. Armstrong RA, Mousavi M. Overview of risk factors for age-related macular degeneration (AMD). J Stem Cells. 2015;10(3):171-191.

5. Yeoh J, Sims J, Guymer RH. A review of drug options in age-related macular degeneration therapy and potential new agents. Expert Opin Pharmacother. 2006;7(17):2355-2368.

6. Khandhadia S, Cherry J, Lotery AJ. Age-related macular degeneration. Adv Exp Med Biol. 2012;724:15-36.

7. Cook HL, Patel PJ, Tufail A. Age-related macular degeneration: diagnosis and management. Br Med Bull. 2008;85:127-149.

8. Ferris III FL, Wilkinson CP, Bird A, et al. Clinical classification of agerelated macular degeneration. Ophthalmology. 2013;120(4):844-851.

9. Rudnicka AR, Jarrar Z, Wormald R, Cook DG, Fletcher A, Owen CG. Age and gender variations in age-related macular degeneration prevalence in populations of European ancestry: a meta-analysis. Ophthalmology. 2012;119(3):571-580.

10. Wang Q, Zhao HS, Li L. Association between complement factor I gene polymorphisms and the risk of age-related macular degeneration: a meta-analysis of literature. Int J Ophthalmol. 2016;9(2):298-305.

11. Wu M, Guo Y, Ma Y, Zheng Z, Wang Q, Zhou X. Association of two polymorphisms, rs1061170 and rs1410996, in complement factor $\mathrm{H}$ with age-related macular degeneration in an Asian population: a metaanalysis. Ophthalmic Res. 2016;55(3):135-144.

12. Thakkinstian A, Han P, McEvoy M, et al. Systematic review and meta-analysis of the association between complement factor $\mathrm{H} \mathrm{Y} 402 \mathrm{H}$ polymorphisms and age-related macular degeneration. Hum Mol Genet. 2006;15(18):2784-2790.

13. Perlee LT, Bansal AT, Gehrs K, et al. Inclusion of genotype with fundus phenotype improves accuracy of predicting choroidal neovascularization and geographic atrophy. Ophthalmology. 2013;120(9):1880-1892.

14. Chen Y, Zeng J, Zhao C, et al. Assessing susceptibility to age-related macular degeneration with genetic markers and environmental factors. Arch Ophthalmol. 2011;129(3):344-351.

15. Velilla S, García-Medina JJ, García-Layana A, et al. Smoking and age-related macular degeneration: review and update. $J$ Ophthalmol. 2013;2013:895147.

16. Myers CE, Klein BE, Gangnon R, Sivakumaran TA, Iyengar SK, Klein R. Cigarette smoking and the natural history of age-related macular degeneration: the Beaver Dam Eye Study. Ophthalmology. 2014; 121:1949-1955.
17. Ni Dhubhghaill SS, Cahill MT, Campbell M, Cassidy L, Humphries MM, Humphries P. The pathophysiology of cigarette smoking and agerelated macular degeneration. Adv Exp Med Biol. 2010;664:437-446.

18. Cano M, Thimmalappula R, Fujihara M, et al. Cigarette smoking, oxidative stress, the anti-oxidant response through Nrf2 signaling, and age-related macular degeneration. Vision Res. 2010;50(7):652-664.

19. Beatty S, Koh H, Phil M, Henson D, Boulton M. The role of oxidative stress in the pathogenesis of age-related macular degeneration. Surv Ophthalmol. 2000;45(2):115-134.

20. Schaumberg DA, Hankinson SE, Guo Q, Rimm E, Hunter DJ. A prospective study of 2 major age-related macular degeneration susceptibility alleles and interactions with modifiable risk factors. Arch Ophthalmol. 2007;125(1):55-62.

21. Rennie CA, Stinge A, King EA, Sothirachagan S, Osmond C, Lotery AJ. Can genetic risk information for age-related macular degeneration influence motivation to stop smoking? A pilot study. Eye (Lond). 2012; 26(1):109-118

22. Guymer RH, Chong EW. Modifiable risk factors for age-related macular degeneration. Med J Aust. 2006;184(9):455-458.

23. Hyman L, Neborsky R. Risk factors for age-related macular degeneration: an update. Curr Opin Ophthalmol. 2002;13(3):171-175.

24. Chakravarthy U, Wong TY, Fletcher A, et al. Clinical risk factors for age-related macular degeneration: a systematic review and metaanalysis. BMC Ophthalmol. 2010;10:31.

25. Ferris FL, Davis MD, Clemons TE, et al. A simplified severity scale for age-related macular degeneration: AREDS Report No. 18. Arch Ophthalmol. 2005;123(11):1570-1574.

26. Simunovic MP. Metamorphopsia and its quantification. Retina. 2015; 35(7):1285-1291.

27. Nowomiejska K, Oleszczuk A, Brzozowska A, et al. M-charts as a tool for quantifying metamorphopsia in age-related macular degeneration treated with the bevacizumab injections. BMC Ophthalmol. 2013;13:13.

28. Goldstein M, Loewenstein A, Barak A, et al. Results of a multicenter clinical trial to evaluate the preferential hyperacuity perimeter for detection of age-related macular degeneration. Retina. 2005;25(3): 296-303.

29. Faes L, Bodmer NS, Bachmann LM, Thiel MA, Schmid MK. Diagnostic accuracy of the Amsler grid and the preferential hyperacuity perimetry in the screening of patients with age-related macular degeneration: systematic review and meta-analysis. Eye (Lond). 2014;28(7): 788-796.

30. Frisén L. The Amsler grid in modern clothes. Br J Ophthalmol. 2009; 93(6):714-716.

31. Díaz-Llopis M, Cervera E, García-Delpech S, Udaondo P, Salom D, Montero J. Rejilla de Amsler versus optotipo de visión próxima y de lectura: autodiagnóstico precoz de la DMAE neovascular. [Amsler grid versus near acuity and reading vision chart: early self-diagnosis in neovascular AMD]. Arch Soc Esp Oftalmol. 2008;83(10):575-578. Spanish.

32. Hageman GS, Gehrs K, Lejnine S, et al. Clinical validation of a genetic model to estimate the risk of developing choroidal neovascular agerelated macular degeneration. Hum Genomics. 2011;5(5):420-440.

33. Perlee LT, Bansal AT, Gehrs K, et al. Inclusion of genotype with fundus phenotype improves accuracy of predicting choroidal neovascularization and geographic atrophy. Ophthalmology. 2013;120(9):1880-1892.

34. Chen Y, Zeng J, Zhao C, et al. Assessing susceptibility to age-related macular degeneration with genetic markers and environmental factors. Arch Ophthalmol. 2011;129(3):344-351.

35. American Academy of Ophthalmology. Age-related macular degeneration PPP-Updated 2015. Available from: https://www.aao.org/ preferred-practice-pattern/age-related-macular-degeneration-ppp-2015. Accessed March 8, 2017.

36. Carneiro Â, Andrade JP. Nutritional and lifestyle interventions for agerelated macular degeneration: a review. Oxid Med Cell Longev. 2017; 2017:6469138.

37. Cong R, Zhou B, Sun Q, Gu H, Tang N, Wang B. Smoking and the risk of age-related macular degeneration: a meta-analysis. Ann Epidemiol. 2008;18(8):647-656. 
38. Rim TH, Cheng CY, Kim DW, Kim SS, Wong TY. A nationwide cohort study of cigarette smoking and risk of neovascular age-related macular degeneration in East Asian men. Br J Ophthalmol. Epub 2017 Mar 14.

39. Brandl C, Breinlich V, Stark KJ, et al. Features of age-related macular degeneration in the general adults and their dependency on age, sex, and smoking: results from the German KORA study. PLoS One. 2016; 11(11):e0167181.

40. Saxena N, George PP, Heng BH, Lim TH, Yong SO. Cost-effectiveness of anti-oxidant vitamins plus zinc treatment to prevent the progression of intermediate age-related macular degeneration. A Singapore perspective. Indian J Ophthalmol. 2015;63(6):516-523.

41. Marshall LL, Roach JM. Prevention and treatment of age-related macular degeneration: an update for pharmacists. Consult Pharm. 2013; 28(11):723-737.

42. Sin HP, Liu DT, Lam DS. Lifestyle modification, nutritional and vitamins supplements for age-related macular degeneration. Acta Ophthalmol. 2013;91(1):6-11.

43. Evans JR, Lawrenson JG. Antioxidant vitamin and mineral supplements for slowing the progression of age-related macular degeneration. Cochrane Database Syst Rev. 2012;11:CD000254.

44. Christen WG, Schaumberg DA, Glynn RJ, Buring JE. Dietary $\omega-3$ fatty acid and fish intake and incident age-related macular degeneration in women. Arch Ophthalmol. 2011;129(7):921-929.

45. Cho E, Hung S, Willett WC, et al. Prospective study of dietary fat and the risk of age-related macular degeneration. Am J Clin Nutr. 2001; 73(2):209-218.

46. Delcourt C, Carrière I, Crstol JP, Lacroux A, Gerber M. Dietary fat and the risk of age-related maculopathy: the POLANUT study. Eur $J$ Clin Nutr. 2007;61(11):1341-1344.

47. Augood C, Chakravarthy U, Young I, et al. Oily fish consumption, dietary docosahexaenoic acid and eicosapentaenoic acid intakes, and associations with neovascular age-related macular degeneration. Am J Clin Nutr. 2008;88(2):398-406.

48. Ho L, van Leeuwen R, Witteman JC, et al. Reducing the genetic risk of age-related macular degeneration with dietary antioxidants, zinc, and

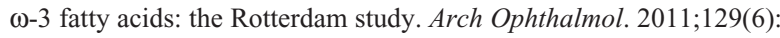
$758-766$.

49. Smith W, Mitchell P, Leeder SR. Dietary fat and fish intake and agerelated maculopathy. Arch Ophthalmol. 2000;118(3):401-404.

50. Tan JS, Wang JJ, Flood V, Mitchell P. Dietary fatty acids and the 10-year incidence of age-related macular degeneration: the Blue Mountains Eye Study. Arch Ophthalmol. 2009;127(5):656-665.

51. Chua B, Flood V, Rochtchina E, Wang JJ, Smith W, Mitchell P. Dietary fatty acids and the 5-year incidence of age-related maculopathy. Arch Ophthalmol. 2006;124:981-986.

52. The Royal College of Ophthalmologists. Age-related macular degeneration: guidelines for management. Available from: https:/www.rcophth. ac.uk/wp-content/uploads/2014/12/2013-SCI-318-RCOphth-AMDGuidelines-Sept-2013-FINAL-2.pdf. Accessed April 9, 2017.
53. Age-Related Eye Disease Study Research Group. A randomized, placebo-controlled, clinical trial of high-dose supplementation with vitamins $\mathrm{C}$ and $\mathrm{E}$, beta carotene, and zinc for age-related macular degeneration and vision loss: AREDS report no. 8. Arch Ophthalmol. 2001; 119(10):1417-1436.

54. Age-Related Eye Disease Study 2 Research Group. Lutein + zeaxanthin and omega-3 fatty acids for age-related macular degeneration: the Age-Related Eye Disease Study 2 (AREDS2) randomized clinical trial. JAMA. 2013;309(19):2005-2015.

55. Seddon JM, George S, Rosner B. Cigarette smoking, fish consumption, omega-3 fatty acid intake, and associations with age-related macular degeneration: the US Twin Study of Age-Related Macular Degeneration. Arch Ophthalmol. 2006;124(7):995-1001.

56. SanGiovanni JP, Agron E, Meleth AD, et al. \{omega\}-3 Long-chain polyunsaturated fatty acid intake and 12-y incidence of neovascular age-related macular degeneration and central geographic atrophy: AREDS report 30, a prospective cohort study from the Age-Related Eye Disease Study. Am J Clin Nutr. 2009;90:1601-1607.

57. Reynolds R, Rosner B, Seddon JM. Dietary omega-3 fatty acids, other fat intake, genetic susceptibility, and progression to incident geographic atrophy. Ophthalmology. 2013;120(5):1020-1028.

58. Souied EH, Aslam T, Garcia-Layana A, et al. Omega-3 fatty acids and age-related macular degeneration. Ophthalmic Res. 2015;55:62-69.

59. Erie JC, Butz JA, Good JA, Erie EA, Burritt MF, Cameron JD. Heavy metal concentrations in human eyes. Am J Ophthalmol. 2005;139(5): 888-893.

60. Satarug S, Kikuchi M, Wisedpanichkij R, et al. Prevention of cadmium accumulation in retinal pigment epithelium with manganese and zinc. Exp Eye Res. 2008;87(6):587-593.

61. Wills NK, Ramanujam VM, Kalariya N, Lewis JR, van Kuijk FJ. Copper and zinc distribution in the human retina: relationship to cadmium accumulation, age, and gender. Exp Eye Res. 2008;87(6):80-88.

62. Wills NK, Kalariya N, Sadagopa Ramanujam VM, et al. Human retinal cadmium accumulation as a factor in the etiology of age-related macular degeneration. Exp Eye Res. 2009;89(1):79-87.

63. Rastmanesh R. Potential of melatonin to treat or prevent age-related macular degeneration through stimulation of telomerase activity. Med Hypothesis. 2011;76(1):79-85.

64. Yi C, Pan X, Yan H, Guo M, Pierpaoli W. Effects of melatonin in agerelated macular degeneration. Ann N Y Acad Sci. 2005;1057:384-392.

65. Crooke A, Huete-Toral F, Colligris B, et al. The role and therapeutic potential of melatonin in age-related ocular diseases. J Pineal Res. Epub 2017 Jun 28

66. Ishikawa M, Jin D, Sawada Y, Abe S, Yoshitomi T. Future therapies of wet age-related macular degeneration. J Ophthalmol. 2015;2015: 138070 .
Clinical Interventions in Aging

\section{Publish your work in this journal}

Clinical Interventions in Aging is an international, peer-reviewed journal focusing on evidence-based reports on the value or lack thereof of treatments intended to prevent or delay the onset of maladaptive correlates of aging in human beings. This journal is indexed on PubMed Central, MedLine,

\section{Dovepress}

CAS, Scopus and the Elsevier Bibliographic databases. The manuscript management system is completely online and includes a very quick and fair peer-review system, which is all easy to use. Visit http://www.dovepress. com/testimonials.php to read real quotes from published authors. 